\title{
Respiratory Diseases of Pregnancy
}

\author{
Daniel M. Glass, Tara Zehrer, and Ali Al-Khafaji
}

\section{Case Presentation}

A 26 year-old gravida 3 para 2 with no known prior medical history presents at 34 weeks gestation to the emergency room with shortness of breath that worsened in the last $24 \mathrm{~h}$. She felt ill for 1 week and had been seen by her primary care provider who treated her symptomatically. Vital signs are remarkable for an oxygen saturation of $82 \%$ on room air and tachycardia. On physical examination, she is tachypneic, using accessory muscles of respiration. Coarse breath sounds are heard on auscultation. She has mild pedal edema. A rapid flu test comes back positive. Chest X-ray shows diffuse interstitial infiltrates (Fig. 99.1). She is admitted to the intensive care unit and started on supplemental oxygen and oseltamivir. A blood gas obtained an hour after admission shows a $\mathrm{PCO}_{2}$ of 40 and $\mathrm{PaO}_{2}$ of 70 on an $\mathrm{FIO}_{2}$ of $100 \%$.

\section{Question}

What is her diagnosis and what is the next most appropriate step in management?

Answer The patient has ARDS associated with Influenza pneumonia. Management should include intubation with precautions for possible difficulty airway. Empiric antibacterial therapy should be started in addition to continued neuraminidase inhibitors.

\section{M. Glass}

Intensivist, Rabin Medical Center, Sackler School of Medicine, Tel Aviv University, Tel Aviv, Israel

T. Zehrer · A. Al-Khafaji $(\bowtie)$

Department of Critical Care Medicine, The CRISMA (Clinical Research, Investigation and Systems Modeling of Acute Illness) Center, University of Pittsburgh School of Medicine,

Pittsburgh, PA, USA

e-mail: alkhafajia2@upmc.edu

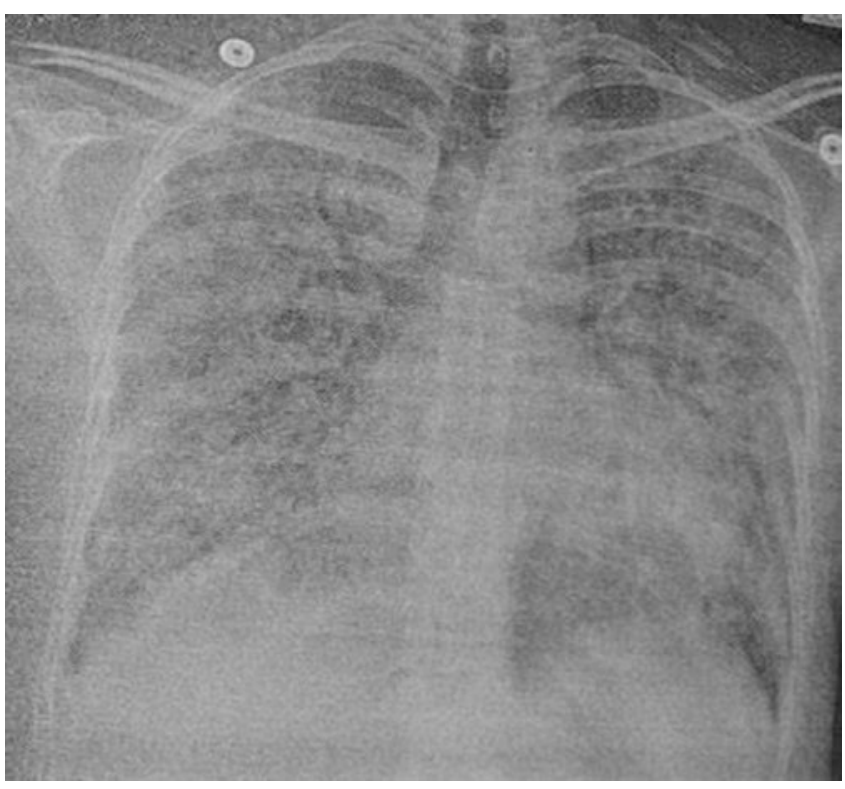

Fig. 99.1 Patient's chest x-ray

\section{Principles of Management}

\section{Physiologic Respiratory Changes Seen in Pregnancy}

Dyspnea on exertion is a common complaint reported by gravid patients as the pregnancy progresses. The etiology is partially explained by the physiologic increase in oxygen consumption by almost $20 \%$ (caused by fetal and uterine demands). However, the body compensates by increasing tidal volume and to a lesser extent respiratory rate $[1,2]$. These changes make the partial pressure of oxygen slightly higher than normal on a blood gas, and would range from 100 to $110 \mathrm{mmHg}$. The partial pressure of carbon dioxide would be lower than normal for a non-pregnant patient and ranges from 27 to $32 \mathrm{mmHg}$ [3]. Low pulmonary reserves that arise from reductions in functional residual capacity 
(caused by the gravid uterus and changes in the chest wall morphology) [1] and increased oxygen consumption make pregnant women develop hypoxemia more rapidly during apnea [4].

\section{Respiratory Pathology during Pregnancy}

\section{Pulmonary Edema}

Pulmonary edema can be broadly classified as cardiogenic or non-cardiogenic. Cardiac output increases very early on and is the highest in the post-partum period. Plasma volume expands due to sodium and water retention, thereby increasing preload, but afterload reduces due to vasodilation [5]. The most common causes of non-cardiogenic acute pulmonary edema in pregnancy are, fluid overload, preeclampsia, tocolytic agents, sepsis, trauma or following aspiration of gastric contents $[6,7]$. Preterm labor increases the risk of pulmonary edema.

\section{Pre-eclampsia associated pulmonary edema}

Pulmonary edema is a frequently encountered complication in patients with pre-eclampsia with most cases occurring after delivery. Initial management involves lowering the blood pressure urgently especially in patients who have severe elevation of blood pressure that persists longer than 15 minutes. Once pulmonary edema occurs, parenteral therapy is more effective, and nitroglycerin is the agent of choice as recommended by The European Society of Cardiology [8]. Diuretics should be instituted to promote preload reduction recognizing that the pre-eclamptic patient may have complex fluid balance needs due to low oncotic pressure. If necessary, noninvasive ventilation is recommended in patients with increased work of breathing or hypoxemia as it is known to improve these parameters and it may decrease the need for invasive mechanical ventilation [9].

\section{Tocolytic Induced Pulmonary Edema}

Pulmonary edema due to tocolytic therapy is relatively uncommon [10]. Terbutaline is a beta agonist that may rarely cause pulmonary edema either through salt retention, tachycardia induced diastolic dysfunction or from fluid overload if infused in a large volume [11]. Management involves stopping the tocolytic therapy and treating pulmonary edema with diuretics. Excessive salt and fluid intake should be avoided. These patients tend to recover well and reported mortality is low [12].

\section{Ovarian Hyperstimulation Syndrome (OHSS)}

OHSS is another uncommon cause of pulmonary edema with a prevalence of $1-10 \%$. Mechanisms are not entirely clear but involve increased vascular permeability. Treatment is supportive care [13].

\section{Aspiration}

Certain factors such as an incompetent lower esophageal sphincter coupled with a decrease in stomach motility can increase the risk for aspiration. One must have a high index of suspicion as not all events are witnessed. Treatment is usually supportive [14].

\section{Peripartum Cardiomyopathy (PPCM)}

PPCM is acute heart failure of uncertain etiology in patients with no known prior heart disease and who typically present in the last month of pregnancy and up to 5 months postpartum. Risk factors include older maternal age, African decent, multiple gestations and hypertension [15]. The mortality rate can be as high as $20-50 \%$ [16, 17].

\section{Airway Disease}

Asthma is seen very frequently with a prevalence in pregnancy ranging from 1 to $8 \%$ [18]. Certain factors easily obtained by a good history can help the clinician understand who is at increased risk of complications from asthma, such as history of exacerbations, intubations, and recent steroid use. Most exacerbations are characterized by cough, wheezing, and dyspnea. The National Asthma Education and Prevention (NAEP) group recommends obtaining a baseline peak expiratory flow in order to guide further management. A target oxygen saturation should be above $90 \%$ with consideration for invasive mechanical ventilation in those who are in impending respiratory failure. A partial pressure of carbon dioxide within the normal range of 36-40 on an arterial blood gas can be an early sign of imminent respiratory failure in the gravid patient. Pharmacotherapy with inhaled beta agonists, inhaled anticholinergics and steroids are identical to that in the non-pregnant patient. Care should be taken during mechanical ventilation to avoid a short expiratory time that can cause auto peep [18]. Intravenous magnesium sulfate may be beneficial in acute severe asthma in addition to bronchodilators especially in patients with coexistent hypertension or preterm uterine contractions [18, 19].

Large airway obstruction mostly arises due to a difficult intubation and the incidence is anywhere between 0.4 and $5.5 \%$. Intubation may be difficult during pregnancy and the peripartum period due to upper airway edema, pharyngeal mucosal friability and diminished airway caliber, especially late in pregnancy. The gravid patient, especially in the third trimester, should be considered a difficult airway patient with high risk of aspiration and decreased oxygen reserve. Other causes of airway obstruction such as tumors, hematoma and laryngeal edema are rarely encountered [20, 21].

\section{Obstructive Sleep Apnea (OSA) in Pregnancy}

Increased upper airway resistance may occur in pregnancy as a result of pharyngeal edema and increased pharyngeal tone could potentially worsen OSA in pregnant women. Incidence 
of OSA is estimated to be between $8.4 \%$ in the first trimester and $19.7 \%$ in the third trimester [22]. Maternal risks include increased morbidity from conditions that have been associated with OSA and underlying obesity such as preeclampsia, eclampsia, gestational hypertension, cardiomyopathy and gestational diabetes [23]. These patients are at higher risk for hypoxemia during labor, and continuous monitoring is necessary. CPAP therapy remains the first line of therapy and women are instructed to bring in their device when they come to the hospital during labor.

\section{Pulmonary Infections in Pregnancy}

\section{Viral Pneumonia}

Varicella and influenza are the most common pathogens associated with viral pneumonia in pregnancy [24]. Estimated mortality rate amongst the $\mathrm{H} 1 \mathrm{~N} 1$ pandemic ranged from 12.5 to $42.1 \%$ [25]. The risk of hospitalization is highest in the third trimester. Mortality related to influenza is mostly due to secondary bacterial pneumonia, although the 2009 $\mathrm{H} 1 \mathrm{~N} 1$ pandemic differed in this aspect with more patients dying primarily from the effects of $\mathrm{H} 1 \mathrm{~N} 1$ virus. The most commonly implicated pathogens are Streptococсис pneumonia and Staphylococcus aureus followed by Hemophilus influenza, and it is reasonable to start empiric antibacterial agents at the time of presentation [26].

\section{Bacterial Pneumonia}

Streptococcus pneumonia followed by Hemophilus Influenza are the most commonly encountered agents [24]. Some of the risk factors for pneumonia in pregnancy include anemia, asthma, antepartum corticosteroids given to enhance fetal lung maturity, and the use of tocolytic agents to induce labor [27]. Oxygen supplementation is necessary with a goal of keeping the partial pressure of oxygen above $70 \mathrm{mmHg}$. Penicillins, cephalosporins, and macrolides are considered safe to use in pregnancy [24]. A history of contact with farm animals should raise suspicion for $\mathrm{Q}$ fever and therapy with macrolides is preferred [28].

\section{Neuromuscular Diseases and Central Causes}

Central causes of respiratory failure such as drugs, tumors, hemorrhage, and infection should be treated for in a similar manner as the general population with treatment of the underlying cause and mechanical ventilation if necessary. Conditions such as kyphoscoliosis may precipitate hypercapnic respiratory failure in pregnancy [29]. These patients should be closely monitored with arterial blood gasses, vital capacity and maximal and minimal inspiratory pressures [30]. Magnesium sulfate, which is used as a tocolytic and to prevent seizures in preeclampsia, can cause respiratory depression at levels greater than $12 \mathrm{mEq} / \mathrm{L}$, and respiratory arrest at levels of 16-18 mEq/L. Careful monitoring of magnesium sulfate dosing and infusion rates, as well as monitoring maternal deep tendon reflexes and urine output, is necessary and achieved with serum magnesium levels at precise infusion rates.

\section{Pneumothorax}

Pneumothorax may occur because of hyperemesis, pushing efforts in labor, underlying lung disease, and without obvious precipitating cause [31]. Hamman's syndrome of intrapartum subcutaneous emphysema, pneumo- mediastinum, or pneumothorax results from the forceful "pushing" efforts during labor and about 200 cases have been reported worldwide before [32]. The clinical presentation is usually chest pain with breathlessness and presence of crackles or "Hamman's sign" in the left lateral decubitus position in systole. Most cases resolve spontaneously, but emergent chest tube placement may be required in some cases.

\section{Pulmonary Embolism in Pregnancy}

Embolic events rank among the major causes of maternal mortality in modern obstetrics. Risk factors include venous stasis, advanced age, sepsis, obesity and cesarean section. Hypoxemia is common. With massive embolism, circulatory failure is more prominent. Diagnosis is made by compression ultrasonography and if negative perfusion study. If the diagnosis of pulmonary embolism is strongly considered, treatment with unfractionated heparin should be started immediately unless high risk or a contraindication is present for the use of anticoagulants. Unfractionated heparin and low-molecular weight heparin are safe to use during pregnancy because they do not cross the placenta. Tissue plasminogen activator has also been used during pregnancy although there are no controlled trials $[33,34]$.

\section{Cystic Fibrosis}

Cystic fibrosis is the most common congenital pulmonary disease encountered during pregnancy. It is a restrictive and obstructive disorder, with a predisposition to infection. Bronchodilators and chest physiotherapy should be recommended, and chest infections should be treated aggressively [35].

\section{Evidence Contour}

\section{Ventilation Strategies in the Pregnant Patient}

Pregnant women have hypocapnia due to hyperventilation at baseline. Thus, the arterial carbon dioxide tension $\left(\mathrm{PaCO}_{2}\right)$ is lower in a pregnant woman, and a normal $\mathrm{PaCO}_{2}$ is a sign of impending respiratory failure. Intubation may be difficult during pregnancy and the peripartum period due to upper airway edema and diminished airway caliber, especially late in pregnancy. 


\section{Goals of Ventilation}

The goal is to rest the fatigued respiratory muscles while providing suitable gas exchange. Respiratory muscle rest involves institution of invasive or noninvasive mechanical support, and the ventilator must overcome pressures related to airway resistance and elastic properties of the lung to allow adequate ventilation and gas exchange. A trial of noninvasive ventilation can be instituted early on in patients with pulmonary edema. Favorable out- comes have been reported in case reports and series [36]. For patients who require intubation and mechanical ventilation, low tidal ventilation strategy is recommended [37]. Positive end expiratory pressure improves oxygenation and should be used to provide a $\mathrm{PaO}_{2}>65 \mathrm{mmHg}$ while administering the least $\mathrm{FiO}_{2}$. The target $\mathrm{PaCO}_{2}$ is $30-32 \mathrm{mmHg}$ since this is the normal level during pregnancy. Marked respiratory alkalosis should be avoided because it may decrease uterine blood flow. Maternal permissive hypercapnia may also be deleterious to the fetus because of resultant fetal respiratory acidosis although this mode of ventilation has been used safely in pregnant women in small trials. Propofol infusion is the sedative drug of choice. If paralytics are indicated, cisatracurium is the preferred agent [38].

\section{Extra Corporeal Membrane Oxygenation (ECMO)}

This technique has been used a rescue therapy for refractory ARDS with reported maternal and fetal survival rates between $80 \%$ and $70 \%$, respectively $[39,40]$. Most of the published literature is from the $2009 \mathrm{H} 1 \mathrm{~N} 1$ influenza pandemic. Early institution with careful patient selection and judicial management of anticoagulation might improve successful outcomes [40, 41].

\section{Prone Ventilation}

Use of prone positioning in the third trimester has not been widely studied however case reports have appeared in the literature with acceptable results. As in other severe ARDS patients, proning requires careful attention to inadvertent decannulation of lines or extubation. The pressure points especially eyes need to be protected attention should be paid avoid hyperextension of joints. There needs to be adequate room for the abdomen to expand passively. This can be achieved by the use of appropriately sized bolsters at chest and hip level to help elevate the patient above the mattress. This also allows for anterior displacement of uterus off of the inferior vena cava, which is necessary for adequate venous return after 20 weeks gestation. Close monitoring of mother and fetus including continuous fetal cardiotocography should be in place if the fetus is of viable age $[42,43]$.

\section{Delivery}

Delivery of the fetus can improve the maternal condition in several obstetrical disease states. In ARDS, it appears perhaps to improve oxygenation and management of the mother but does not definitively improve maternal survival [37, 44].

\section{Box 99.1}

Differential Diagnosis of Pulmonary

Conditions in Pregnancy

Conditions Unique to Pregnancy

Pulmonary edema.

- Pre-eclampsia related

- Tocolytic induced pulmonary edema

- Peripartum cardiomyopathy

- Ovarian hyper stimulation syndrome

- Mendelson syndrome

- Amniotic emboli

Conditions not Unique to Pregnancy

Exacerbation of underlying pulmonary conditions

- Asthma

- Obstructive sleep apnea

- Pulmonary infections

- Pulmonary emboli

- ARDS secondary to trauma, burns, sepsis

Acknowledgment Conflict of Interest: None. Financial Support: None.

\section{References}

1. Hegewald MJ, Crapo RO. Respiratory physiology in pregnancy. Clin Chest Med. 2011:32(1). https://doi.org/10.1016/j.ccm.2010.11.001.

2. Crapo RO. Normal cardiopulmonary physiology during pregnancy. Clin Obstet Gynecol. 1996;39(1):3-16.

3. Templeton A, Kelman GR. Maternal blood-gases, PAo2--Pao2), physiological shunt and VD/VT in normal pregnancy. Br J Anaesth. 1976;48(10):1001-4.

4. Archer GW, Marx GF. Arterial oxygen tension during apnoea in parturient women. Br J Anaesth. 1974;46(5):358.

5. Benedetti TJ, Carlson RW. Studies of colloid osmotic pressure in pregnancy-induced hypertension. Am J Obstet Gynecol. 1979;135(3):308-11.

6. Bandi VD, Munnur U, Matthay MA. Acute lung injury and acute respiratory distress syndrome in pregnancy. Crit Care Clin. 2004;20:577-607. 
7. Vasquez DN, Estenssoro E, Canales HS, et al. Clinical characteristics and outcomes of obstetric patients requiring icu admission. Chest. 2007;131(3):718-24.

8. Melchiorre K, Sharma R, Thilaganathan B. Cardiovascular implications in preeclampsia: an overview. Circulation. 2014;130(8): 703-14.

9. Dennis AT, Solnordal CB. Acute pulmonary oedema in pregnant women. Anaesthesia. 2012;67:646-59. 89 Respiratory Diseases of Pregnancy.

10. Bowen RE, Dedhia HV, Beatty J, Schiebel F, Koss W, Granado J. ARDS associated with the use of sympathomimetics and glucocorticoids for the treatment of premature labor. Crit Care Med. 1983;11(8):671-2.

11. Lamont RF. The pathophysiology of pulmonary oedema with the use of beta-agonists. BJOG. 2000;107(4):439-44.

12. DiFederico EM, Burlingame JM, Kilpatrick SJ, Harrison M, Matthay MA. Pulmonary edema in obstetric patients is rapidly resolved except in the presence of infection or of nitroglycerin tocolysis after open fetal surgery. Am J Obstet Gynecol. 1998;179(4):925-33.

13. Brinsden PR, Wada I, Tan SL, et al. Diagnosis, prevention and management of ovarian hyperstimulation syndrome. Br J Obstet Gynaecol. 1995;102:767-72.

14. Ashe Jr JR. Pulmonary aspiration-a life-threatening complication in obstetrics. N C Med J. 1976;37(12):655-7.

15. Davis M, Duvernoy C. Peripartum cardiomyopathy: current knowledge and future directions. Womens Health (Lond). 2015;11(4):565-73.

16. Pearson GD, Veille JC, Rahimtoola S, et al. Peripartum cardiomyopathy: National Heart, Lung and Blood Institute and Office of Rare Diseases (National Institutes of Health) workshop recommendations and review. JAMA. 2000;283:1183.

17. Sciscione AC, Ivester T, Largoza M, Manley J, Shlossman P, Colmorgen GH. Acute pulmonary edema in pregnancy. Obstet Gynecol. 2003;101(3):511-5.

18. Murphy VE, Gibson PG, Smith R, Clifton VL. Asthma during pregnancy: mechanisms and treatment implications. Eur Respir J. 2005;25(4):731.

19. Clark SL. Asthma in pregnancy. National Asthma Education Program Working Group on Asthma and Pregnancy. National Institutes of Health, National Heart, Lung, and Blood Institute. Obstet Gynecol. 1993;82(6):1036-40.

20. McKeen DM, George RB, O'Connell CM, Allen VM, Yazer M, Wilson M, Phu TC. Difficult and failed intubation: Incident rates and maternal, obstetrical, and anesthetic predictors. Can J Anaesth. 2011;58(6):514-24.

21. Biro P. Difficult intubation in pregnancy. Curr Opin Anaethesiol. 2011;24(3):249-54.

22. Pien GW, Pack AI, Jackson N, Maislin G, Macones GA, Schwab RJ. Risk factors for sleep-disordered breathing in pregnancy. Thorax. 2014;69(4):371-7. Epub 2013 Nov 21.

23. Pamidi S, Pinto LM, Marc I, Benedetti A, Schwartzman K, Kimoff RJ. Maternal sleep-disordered Breathing and adverse pregnancy outcomes: a systematic review and meta-analysis. Am J Obstet Gynecol. 2014;210(1):52.e1-52.

24. Goodnight WH, Soper DE. Pneumonia in pregnancy. Crit Care Med. 2005:33(10(Suppl)). https://doi.org/10.1097/01. CCM.0000182483.24836.66.
25. Siston AM, Rasmussen SA, Honein MA, Fry AM, Seib K, Callaghan WM, Louie J, Doyle TJ, et al. Pandemic 2009 influenza A(H1N1) virus illness among pregnant women in the United States. JAMA. 2010;303(15):1517-25. https://doi.org/10.1001/jama.2010.479.

26. Petersdorf RG, Fusco JJ, Harter DH, Albrink WS. Pulmonary infections complicating Asian influenza. AMA Arch Intern Med. 1959;103:262-72.

27. Lim WS, Macfarlane JT, Colthorpe CL. Pneumonia and pregnancy. Thorax. 2001;56:398-405. https://doi.org/10.1136/thorax.56.5.398.

28. Benedetti TJ, Valle R, Ledger WJ. Antepartum pneumonia in pregnancy. Am J Obstet Gynecol. 1982;144:413-7.

29. Leighton B, Fish J. Pulmonary disease in pregnancy glob. Libr Women Med (ISSN: 1756-2228). 2008. https://doi.org/10.3843/ GLOWM.10170.

30. Shneerson JM, Simonds AK. Noninvasive ventilation for chest wall and neuromuscular disorders. ERJ. 2002;20(2):480-7. https://doi. org/10.1183/09031936.02.00404002.

31. Andrew McGregor A, Ogwu C, Uppal T, Wong GM. Spontaneous subcutaneous emphysema and pneumo- mediastinum during second stage of labour. BMJ Case Rep. 2011. https://doi.org/10.1136/ bcr.04.2011.4067.

32. Heffner JE, Sahn SA. Pleural disease in pregnancy. Clin Chest Med. 1992;13(4):667-78.

33. Heit JA, Kobbervig CE, James AH, Petterson TM, Bailey KR, Melton 3rd LJ. Trends in the incidence of venous thromboembolism during pregnancy or postpartum: a 30-year population-based study. Ann Intern Med. 2005;143(10):697-706.

34. Liu S, Rouleau J, Joseph KS, et al. Epidemiology of pregnancyassociated venous thromboembolism: a population-based study in Canada. J Obstet Gynaecol Can. 2009;31(7):611-20.

35. Bhatia P, Bhatia K. Pregnancy and the lungs. Postgrad Med J. 2000;76:683-9. https://doi.org/10.1136/pmj.76.901.683.

36. Allred CC, Esquinas AM, Caronia J, Mahdavi R, Mina BA. Successful use of noninvasive ventilation in pregnancy. Eur Respir Rev. 2014 https://doi.org/10.1183/09059180.00008113.

37. Campbell LA, Klocke RA. Implications for the pregnant patient. Am J Respir Crit Care Med. 2001;163:1051-4.

38. Pacheco LD, Saade GR, Hankins GDV. Mechanical ventilation during pregnancy: sedation, analgesia, and paralysis. Clin Obstet Gynecol. 2014;57(4):844-50.

39. Afessa B, Green B, Delke I, Koch K. Systemic inflammatory response syndrome, organ failure, and outcome in critically ill obstetric patients treated in an icu. Chest. 2001;120(4):1271-7.

40. Nair P, Davies AR, Beca J, et al. Extracorporeal membrane oxygenation for severe ARDS in pregnant and postpartum women during the 2009 H1N1 pandemic. Intensive Care Med. 2011;37:648-54.

41. Nirmal S, Wille KM, Bellot SC, et al. Modern use of extracorporeal life support in pregnancy and postpartum. Sharma Am Soc Artif Int Organs. 2015;61(1):110-4.

42. Kenn S, Weber-Carstens S, Weizsaecker K, Bercker S. Prone positioning for ARDS following blunt chest trauma in late pregnancy. Int J Obstet Anesth. 2009;18(3):268-71.

43. Samanta S, Samanta S, Wig J, Baronia AK. How safe is the prone position in acute respiratory distress syndrome at late pregnancy. Am J Emerg Med. 2014;32(6):687.e1-3.

44. Tomlinson MW, Caruthers TJ, Whitty JE, Gonik B. Does delivery improve maternal condition in the respiratory-compromised gravida? Obstet Gynecol. 1998;91:108-11. 